Basher et al., 2009

Stamford Journal of Pharmaceutical Sciences

\section{Comparative Evaluation of HPMC, PVA and Gelatin as Matrices for Controlled Release Drug Delivery}

\author{
Mohammad Anwarul Basher ${ }^{1^{*}}$, Abul Kalam Lutful Kabir ${ }^{2}$, Mohammad \\ Musarraf Hussain ${ }^{1}$, Mir Mohammad Abdullah Al Mamun ${ }^{3}$ \\ Department of Pharmacy, Noakhali Science and Technology University ${ }^{1}$ \\ Sonapur, Noakhali-3802, Bangladesh \\ Department of Pharmacy, Stamford University Bangladesh ${ }^{2}$ \\ 51, Siddeswari Road, Dhaka-1217, Bangladesh \\ Production Officer, Square Pharmaceuticals $\mathrm{Ltd}^{3}$ \\ Gazipur, Dhaka.
}

*Corresponding Author

Mohammad Anwarul Basher Lecturer, Dept. of Pharmacy

Noakhali Science and Technology University

Contact no.: +8801726742586

Email: mabasher@live.com

Received- 2 Decebmer, 2008

Accepted for Publication- 22 April, 2009

\begin{abstract}
The present study was undertaken to compare three different polymeric gums- HPMC, PVA and gelatin as controlled release matrices. Diclofenac sodium, a potent analgesic, was used as the model drug. Different ratio of HPMC, PVA and gelatin were incorporated into the lactose loaded Diclofenac tablet to explore their impact on drug release. Matrix tablets of Diclofenac were prepared by using individual polymer with magnesium stearate and aerosil by direct compression process at 5 ton pressure. The release of drug from these matrices was studied over 2 hrs in acidic media where insignificant release was observed. Then, the same formulations were studied over 8 hours in buffer media of $\mathrm{pH} 6.8$ at a temperature of $37 \pm 0.5^{\circ} \mathrm{C}$. Statistically significant differences in drug release profile was found among the tablets prepared from different matrices. The study revealed that the average \% release of drug from different types of polymer loaded matrix tablet varied with the ratio of different polymers. Among the three polymers, PVA showed best dissolution pattern. A comparison of Higuchi curve and bi-exponential curve was also performed.
\end{abstract}

Key words: HPMC, PVA, Gelatin, Controlled release, Diclofenac

\title{
INTRODUCTION
}

With many drugs, the basic goal of therapy is to achieve a steady-state blood or tissue level that is therapeutically effective and non-toxic for an extended period of time. The design of proper dosage regimen is an important element in accomplishing this goal. A basic objective is to optimize the delivery of medication so as to achieve a measure of control of the therapeutic effect in the face of uncertain fluctuations in the in vitro environment in which drug release takes place (Lachman et al.1976). Now a day, a great deal of attention has been paid to controlled release drug delivery system in which control of drug action through formulation implies controlling bioavailability to reduce drug absorption rates. The term "controlled release" is defined as those systems from which therapeutic agents may be automatically delivered as predefined rates over a long period of time. Products of this type have been formulated for oral, parenteral and topical use, and include inserts for placement in body cavities as well (Ballard B.E.1978). The most important property of a dosage form is its ability to deliver the active ingredient to the site of action in an amount of sufficient to elicit desired effect. Controlled release drug delivery system may have the profound advantage to this purpose. To maintain the most favorable condition and to control the drug release rate, several types of oral dosage forms have been introduced. The simplest of these is matrix tablet where a drug is dispensed in a polymer and the polymer acts as a matrix (Solomon et al.1980; Chowhan Z.1980; Rowe R.C.1977). Matrix tablet formulation involves the direct compression of blends of drug, retardant material and additives to form a tablet in which drug is embedded in a matrix core of the retardant. Drug bioavailability is modified by inclusion of diluents such as lactose and other excipients (Solomon et al.1980; Chowhan Z.1980; Rowe R.C.1977). Drug concentration, aqueous solubility, molecular size, crystal form etc. must also be taken under consideration in order to design a delivery system that exhibits controlled release characteristics (Adkin et al.1997; Capan Y.1989).Two general set of methods have been developed for implementation of practical controlled release dosage form design- methods based on modification 
of the physical and/or chemical properties of the drugs, and methods based on modification of the drug release rate characteristics of the drug (Sinkula.1978). The formulation methods used to obtain the desired drug availability rate from sustained release dosage include increased particle size of the drug, embedding the drug in matrix system and coating the drug or dosage form (Baker et al.1974).

Three different polymers- HPMC $10000 \mathrm{cps}$, PVA and gelatin were evaluated as matrices for controlled release. HPMC is white fibrous, odorless and tasteless powder. It is used as colloid protective agent, emulsifying agent and dispersing agent. PVA occurs as odorless, white to creamcolored granular powder. It is used as a coating agent, lubricant, stabilizing agent and viscosity imparting agent. Gelatin occurs as light-amber or faintly yellow-colored, vitreous, brittle solid. It is used as a coating agent, film former, gelling agent, suspending agent, tablet binder and viscosity increasing agent (Kibbe.1998). The active ingredient taken in the formulation of this controlled release formulation is Diclofenac. Diclofenac is a potent analgesic and anti-inflammatory drug ${ }^{12}$. It inhibits cyclooxygenase enzyme, thus inhibiting the synthesis of prostaglandins. Diclofenac is indicated for rheumatoid arthritis, osteoarthritis, ankylosing spondolytis, tenditis, acute musculoskeletal injury and postoperative patient (Goodman \& Gilman's-The Pharmaceutical basis of Therapeutics, 1998).

\section{EXPERIMENTAL}

\section{Preparation of matrix tablet}

Active ingredient with hydrophilic materials, filler, lubricant and flow promoter was blended by method of dry blending followed by direct compression. The nine formulae of the tablets with their codes are listed in the table 1. In all cases the amount active ingredient was $100 \mathrm{mg}$ and total weight of each tablet was $352 \mathrm{mg}$. Drug, lactose, magnesium stearate, aerosol and matrix forming agent (HPMC, PVA and gelatin) were weighted and blended in a laboratory mixer for 10 minutes. After proper mixing the appropriate amount of the mixture was compressed with a $13 \mathrm{~mm}$ flat punch and die set under 5 tons compression force for 2 seconds. Before compression the surface of the die punch was lubricated with $\mathrm{Mg}$ stearate. Prepared tablets were kept in an air tight container at room temperature ${ }^{14}$.

Table 1: Formulae of polymer loaded Diclofenac-Na tablet

\begin{tabular}{llllllll}
\hline $\begin{array}{l}\text { Formula } \\
\text { No. }\end{array}$ & $\begin{array}{l}\text { Diclofenac-Na } \\
(\mathrm{mg})\end{array}$ & \multicolumn{3}{c}{ Polymers } & \multicolumn{3}{c}{ Excipients } \\
\cline { 3 - 8 } & & $\begin{array}{l}\text { HPMC } \\
(\mathrm{mg})\end{array}$ & $\begin{array}{l}\text { PVA } \\
(\mathrm{mg})\end{array}$ & $\begin{array}{l}\text { Gelatin } \\
(\mathrm{mg})\end{array}$ & $\begin{array}{l}\text { Lactose } \\
(\mathrm{mg})\end{array}$ & $\begin{array}{l}\text { Mg- } \\
\text { stearate } \\
(\mathrm{mg})\end{array}$ & $\begin{array}{l}\text { Aerosil } \\
(\mathrm{mg})\end{array}$ \\
\hline F-1 & 100 & 50 & - & - & 200 & 1 & 1 \\
F-2 & 100 & - & 50 & - & 200 & 1 & 1 \\
F-3 & 100 & - & - & 50 & 200 & 1 & 1 \\
F-4 & 100 & 100 & - & - & 150 & 1 & 1 \\
F-5 & 100 & - & 100 & - & 150 & 1 & 1 \\
F-6 & 100 & - & - & 100 & 150 & 1 & 1 \\
F-7 & 100 & 150 & - & - & 100 & 1 & 1 \\
F-8 & 100 & - & 150 & - & 100 & 1 & 1 \\
F-9 & 100 & - & - & 150 & 100 & 1 & 1 \\
\hline
\end{tabular}

\section{Dissolution studies}

Dissolution of prepared matrix tablets was conducted using a station USP XXIII type II apparatus at $37 \pm 0.5^{\circ} \mathrm{C}$ at $50 \mathrm{rpm}$ speed. Dissolution studies were carried out in phosphate buffer of pH 6.8 for $8 \mathrm{hrs}$ under sink condition. At every one hour interval $5 \mathrm{ml}$ of sample solution were withdrawn from each dissolution basket and equal volume of buffer was added to maintain the volume constant. The sample solutions were analyzed at $277 \mathrm{~nm}$ by a single beam UV spectrophotometer. The amount of drug present in the sample was calculated with the help of appropriate calibration curve of standard drug constructed as percent release verses time (hrs) curve. 


\section{RESUTLS AND DISCUSSION}

Study of release kinetics (zero-order, Higuchi and Bi-exponential) of HPMC, PVA and gelatin The duration of existence of drug inside the body can measured in terms of dissolution rate. Two objectives in the development of in vitro dissolution tests are i) to show that the release of the drug from the tablet is as close as possible to $100 \%$ ii) to show that the rate of drug release is uniform from batch to batch and is the same as the release rate from those batches proven to be bioavailable and clinically effective. After preparing the tablets, their release profiles were studied using buffer solution of $\mathrm{pH} 6.8$ as dissolution medium. Six tablets from each formulation were considered in the study. The release data were treated in different fashion to identify the release pattern. Different graphs were plotted from dissolution data. Zero order curve was obtained by plotting $\%$ release vs. time. Higuchi plot was obtained by plotting $\%$ release vs. square root of time.

Table 2: Observation of the average \% release in polymer loaded matrix tablet

\begin{tabular}{llllllllll}
\hline $\begin{array}{l}\text { Time } \\
\text { interval }\end{array}$ & \multicolumn{10}{c}{ Average \% release } \\
& F-1 & F-2 & F-3 & F-4 & F-5 & F-6 & F-7 & F-8 & F-9 \\
\hline $1 \mathrm{hr}$ & 38.3 & 60.4 & 75.1 & 9.8 & 29.5 & 30.6 & 7.6 & 22.1 & 18.7 \\
$2 \mathrm{hr}$ & 52.0 & 61.3 & 76.4 & 19.2 & 33.1 & 34.3 & 14.7 & 26.1 & 22.4 \\
$3 \mathrm{hr}$ & 62.6 & 63.7 & 77.5 & 26.5 & 34.7 & 35.5 & 19.6 & 30.1 & 25.9 \\
$4 \mathrm{hr}$ & 64.2 & 65.1 & 77.9 & 32.0 & 36.8 & 36.7 & 25.4 & 32.8 & 29.5 \\
$5 \mathrm{hr}$ & 68.8 & 66.4 & 78.7 & 37.3 & 36.7 & 37.7 & 30.2 & 34.8 & 34.0 \\
$6 \mathrm{hr}$ & 70.7 & 68.4 & 79.8 & 38.7 & 47.6 & 37.8 & 34.5 & 36.3 & 36.6 \\
$7 \mathrm{hr}$ & 71.8 & 69.5 & 80.6 & 46.6 & 51.0 & 38.4 & 37.5 & 37.5 & 37.0 \\
$8 \mathrm{hr}$ & 72.7 & 71.0 & 81.7 & 52.1 & 52.4 & 39.5 & 40.0 & 37.3 & 39.5 \\
\hline
\end{tabular}

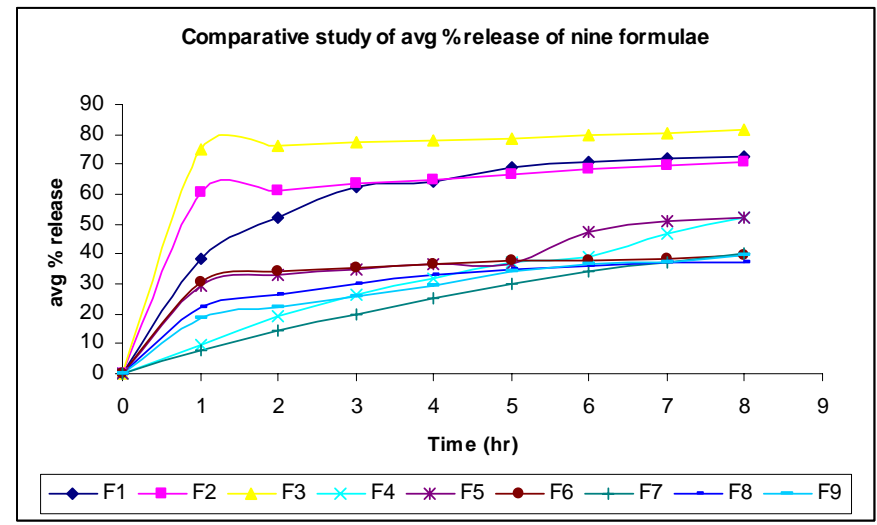

Figure 1: Comparative study of average $\%$ release of nine formulations

From table 2, the tablets (formula no. F-1, F-4 and F-7) prepared by HPMC, as the amount of polymer increases, the drug release drastically falls. With $50 \mathrm{mg}$ HPMC, about $38 \%$ drug was released whereas only $10 \%$ and $8 \%$ were released at first hour for formulation F-4 and F-7. In cases of tablets formulated with PVA and gelatin, same release patterns were observed. Out of these three polymers, gelatin showed maximum release at first hour $(75 \%)$ and the release was continued steadily to about $82 \%$ after eighth hour.

Table 3: Measurement of different release parameters for polymer loaded matrix tablet

\begin{tabular}{lllllll}
\hline Formula No. & \multicolumn{3}{l}{ From Higuchi curve } & \multicolumn{5}{l}{ From Bi-exponential curve } \\
\cline { 2 - 7 } & Slope $(\mathrm{m})$ & Constant $(\mathrm{c})$ & $\mathrm{R}^{2}$ & Slope $(\mathrm{m})$ & Constant $(\mathrm{c})$ & $\mathrm{R}^{2}$ \\
\hline F-1 & 25.33 & 9.83 & 0.92 & 0.30 & -0.39 & 0.94 \\
F-2 & 21.02 & 20.39 & 0.72 & 0.08 & -0.23 & 0.93 \\
F-3 & 23.52 & 27.20 & 0.65 & 0.04 & -0.13 & 0.93 \\
F-4 & 18.69 & -4.70 & 0.97 & 0.77 & -0.97 & 0.99 \\
F-5 & 16.93 & 5.19 & 0.93 & 0.28 & -0.56 & 0.82 \\
F-6 & 9.15 & 31.09 & 0.98 & 0.11 & -0.51 & 0.98 \\
F-7 & 15.19 & -4.19 & 0.97 & 0.80 & -1.09 & 0.99 \\
F-8 & 12.8 & 5.41 & 0.93 & 0.27 & -0.65 & 0.99 \\
F-9 & 24.18 & 16.57 & 0.96 & 0.38 & -0.75 & 0.98 \\
\hline
\end{tabular}




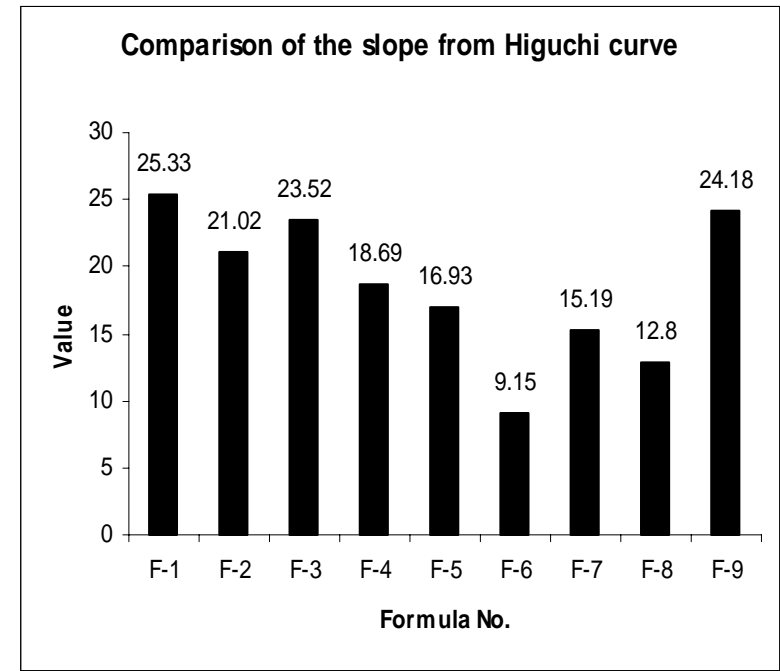

Figure 2. Comparison of the slope from Higuchi curve

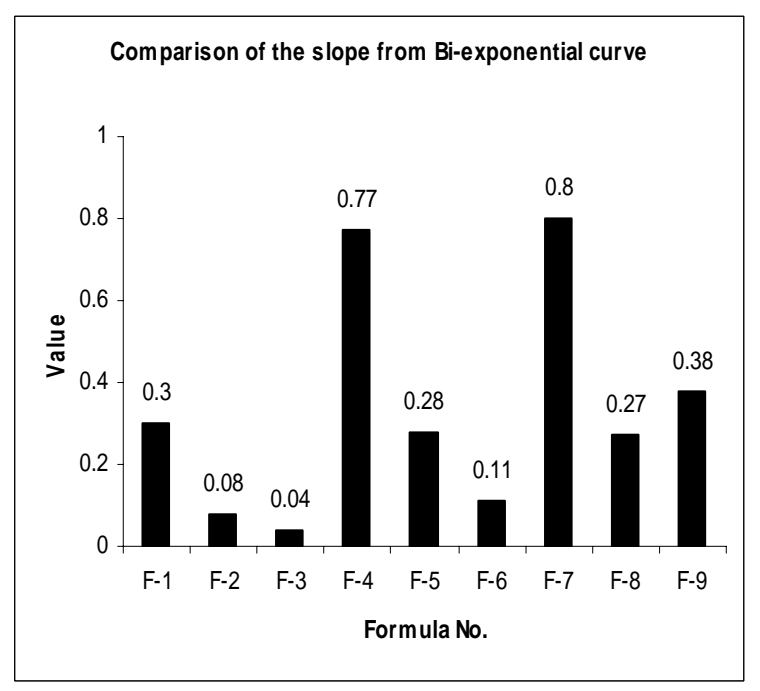

Figure 3. Comparison of the slope from Biexponential curve

Study of flow properties of powder materials individually and in combination with the same ratio as in formulation

In this study, angle of repose $\left(\mathrm{AR}^{\circ}\right)$ was considered as an indirect indication of flow properties. Angle of repose $<20^{\circ}$ shows excellent flow property whereas $>40^{\circ}$ shows very poor flowability comparatively. Angle of repose can be expressed by the following formula-

$$
\mathrm{AR}^{\circ}=\tan ^{-1}(H / R) \text {; here, } \mathrm{H}=\text { maximum cone height } \& \mathrm{R}=\text { radius of the cylinder }
$$

The polymers, active ingredient and other excipients were mixed in different combinations and their angle of repose was measured. The combinations were given in Table 4.

Table 4: Angle of repose of individual polymer and in combination with lactose

\begin{tabular}{lc}
\hline Ingredients & Angle of repose \\
\hline HPMC & $18^{\circ}$ \\
Lactose: HPMC (4:1) & $17^{\circ}$ \\
Lactose: HPMC (3:2) & $18^{\circ}$ \\
Lactose: HPMC (2:3) & $23^{\circ}$ \\
PVA & $17^{\circ}$ \\
Lactose: PVA (4:1) & $21^{\circ}$ \\
Lactose: PVA (3:2) & $18^{\circ}$ \\
Lactose: PVA (2:3) & $16^{\circ}$ \\
Gelatin & $18^{\circ}$ \\
Lactose: Gelatin (4:1) & $21^{\circ}$ \\
Lactose: Gelatin (3:2) & $14^{\circ}$ \\
Lactose: Gelatin (2:3) & $18^{\circ}$ \\
\hline
\end{tabular}

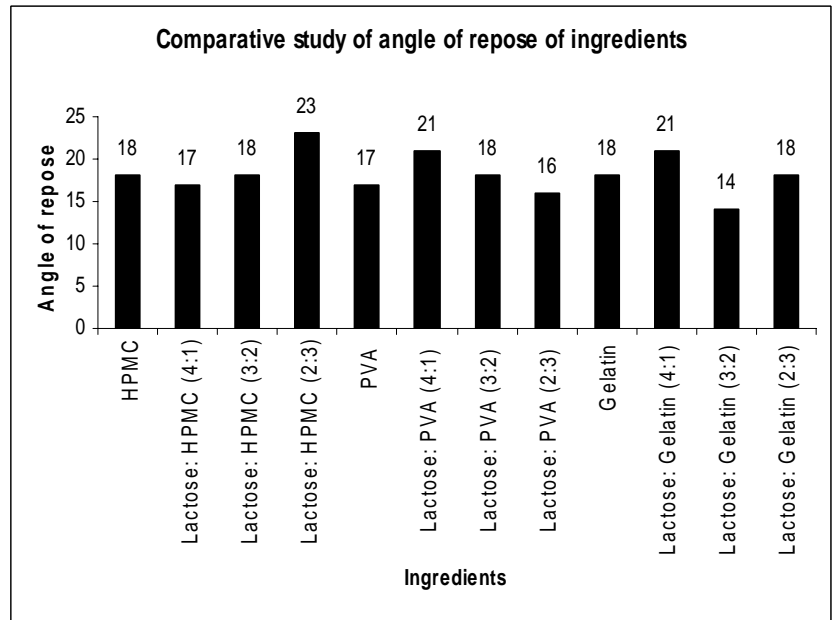

Figure 4: Comparative study of angle of repose of ingredients

HPMC showed good flow property. But in combination with lactose, the flow property decreases as the ratio of weight of HPMC increases. On the other hand, PVA has also good flow property. But it showed exactly opposite flow pattern in comparison with HPMC. The flow property increases as the ratio of weight of PVA increases. $n$ case of gelatin, the mixtures showed variable angle of repose. 


\section{CONCLUSION}

The present study was undertaken to compare of three different hydrophilic gums as matrix for controlled release dosage form. Diclofenac sodium tablet in combination with polymeric substances show good controlled release dosage form. After statistical analysis of all variable data generated in this study, it is clear that proper selection of proper amount of matrix forming agent (polymer) is an important consideration in designing matrix tablet with desired dissolution profile. From the data analysis of different flow property of powder materials of polymeric substances, it is revealed that different polymeric substances individually and in combination with diluents show good flow property. However, a number of critical parameters such as granulation process, tableting conditions, hardness and porosity of the tablet and compression pressure will markedly affect drug release pattern from these matrices. These factors, although beyond the scope of this study, should be taken into consideration during formulation design.

\section{REFERENCES}

Adkin D.A, Kenyon C.J, Lerner E.I, Landau I and Wilding I.R.(1997) Use of scintigraphy to provide proof of concept for novel polysaccharide preparations designed for colonic drug delivery. Pharm. Res.14:103-107.

Baker R.W and Lonsdale H.K.(1974) Controlled release: Mechanisms and rates. In advances in experimental medicine and biology, New York, Plenum Press.47:433.

Ballard B.E.(1978) An overview of prolonged action drug dosage forms: Sustained and controlled release drug delivery systems, New York. Marcel Dekker.

Capan Y.(1989) Influence of technological factors on formulation of sustained release tablet. $J$. Drug development and industrial pharmacy.15: 927-957.

Chowhan Z.T.(1980) Role of binders in moisture-induced hardness increase in compressed tablets and its effect on it vitro disintegration and dissolution. J. Pharm. Sci.69:1-4.

Feinstein W and Bartilucci A.J.(1966) Comparative study of selected disintegrating agents. J Pharm Sci.55: 332-334.

Goodman \& Gilman's The Pharmaceutical Basis of Therapeutics.(1998) $9^{\text {th }}$ Ed. pp.636-637.

Kibbe A.H.(1996) Handbook of Pharmaceutical excipients, $34^{\text {th }}$ Ed. pp599-601.

Lachman L, Lieberman H.A. and Kanig J.L. (1976) The theory and practice of industrial pharmacy., $3^{\text {rd }}$ Ed. pp.430-456 Lea and Febiger.

Lund W.(1994) Monographs on drug substances: Diclofenac sodium. The Pharmaceutical Codex. The Pharmaceutical Press, London.12:835-838.

Rowe R.C.(1977) The adhesion of film coatings to tablet surfaces- the effect of some direct compression excipients and lubricants. J. Pharmacology.29:723-726.

Salomon J.L and Doelker E.(1980) Effect of drug and polymer ratio in low-milligram potency formulations, J. Pharm. Sci. 55:174.

Sinkula A.A.(1978) Methods to achieve sustained drug delivery-the chemical approach. In sustained and controlled release drug delivery systems. Edited by J.R. Robinson. New York, Marcel Dekker.47:433. 